\title{
Sectors together for professional development: a university team in an action research collaboration with school teachers and senior leaders
}

\author{
Adewale Magaji ${ }^{1}$, Ana Cabral ${ }^{2}$, Andrew Lambirth ${ }^{1}$, Roger McDonald ${ }^{1}$, Ashley Brett ${ }^{1}$, \\ Christopher Philpott ${ }^{1}$ \\ University of Greenwich ${ }^{1}$, Queen Mary University of London², UK \\ Corresponding author: A.Magaji@greenwich.ac.uk
}

\begin{abstract}
Action research promotes teaching and learning as it may allow teachers to explore areas of their practices that require improvement. The purpose of this case study is to highlight the steps involved in carrying out action research and any challenges that teachers may encounter in this learning process. This study was developed as a professional development course from 2015 to 2019 attended by more than 150 teachers from early years, primary and secondary schools in London and Kent in the last 4 years. The teachers were registered as students at the University of Greenwich and supported by a university team of researchers. The study identified five steps of the development of teacher-led action research and highlighted the challenges for each step. The steps included defining the field of action; planning; action; evaluation and reflection/(re)planning. This led to the development of an innovative model for the facilitation of action research and collaboration between the university team and participants. The model is used as a framework to enhance the development of teacher-led research in schools.
\end{abstract}

Keywords: action research, teacher-led research, models, collaboration

\section{Introduction}

The landscape of teacher development in England began changing because of a wholesystem reform and structural change, with teaching school alliances and multi-academy trusts promoting the development of teacher-led research in schools. Research carried out with and by teachers has become increasingly significant in efforts to improve the quality of teaching (BERA, 2014; DfE 2014; NCTL, 2015) and learning. It is not, therefore, surprising to see that such school alliances and academies are beginning to include in teachers' contracts the need to commit to undertaking action research (NTR, 2011) to improve their development. This contractual change may in part represent a new way of supporting teachers, though, arguably, some teachers in a sector not traditionally research-orientated may regard it as an intrusive and authoritarian measure, especially if their inclination is to teach and not research. If teachers lack research knowledge, their continuing professional development (CPD) preference may well be for one-day training run by the school or other agency rather than for engaging themselves in action research. However, experience suggests that action research by classroom practitioners into aspects of their working context is more likely to result in informed, relevant findings that lead to successful strategies for improvement. 
School improvement requirements have been identified as a driving force in encouraging teachers in participating in action research (Bryan \& Burstow, 2016) by working with researchers in the university as this gives them the agency in deciding on their professional development needs and how to improve them. However, Biesta et al. (2015) reported a mixed feeling about teacher agency in terms of their professional development as a driving force in school improvement as we know that some teachers may be reluctant in engaging in action research.

In this case study, we argue for collaborative learning, supported by a team from the University of Greenwich, to provide requested professional development for teachers in the form of an action research approach (Carr \& Kemmis, 1986; Kemmis, 2010; Cordingley, 2013) to enhance pedagogy and explore the process and the challenges of such a strategy.

\section{Theoretically framing the literature}

A pedagogical shift to classroom-based research may require schoolteachers in England to engage in action research to improve their practices (Cordingley, 2013). At the heart of this is the need for collaboration between experts from university, teachers and senior leaders in facilitating the process of action research. This has been emphasised by the DFE's (2016) standard for teachers' professional development. Action research will advance teachers' pedagogy (Kemmis, 2010) and Bleicher (2014) considers this professional learning as an active process as it may change their knowledge bases, beliefs and practices. It provides teachers with the agency to accentuate their development in a collaborative environment fostering professional relationships with experts from the university (Mockler \& GroundwaterSmith, 2015) towards learning enhancement and school improvement. The teachers will be able to develop the research knowledge and skills to improve their practices.

Carr \& Kemmis (1986) propose three approaches to action research such as technical, practical and emancipatory action research. Our work with teachers focuses on practical action research (PAR), however, aspects of other approaches cannot be dismissed. Carr \& Kemmis (1986) describe action research as being about the understanding of the practice and the improvement of the situation in which the practice takes place. Consequently, Kemmis, McTaggart \& Nixon (2014) suggest the following stages as informing an action research cycle; reflect, plan, act, observe and reflect. These are important in supporting teachers as researchers and helping them to work effectively with the university research team. However, to achieve a collaborative learning process, Lofthouse et al's. (2016) model of conceptualising collaborative action research involving the zones of collaborative, contributory and proximal activities was utilised in this study to promote learning among the teachers. This will be discussed in the implementation section.

\section{Description of the participants}

In 2015, a group of school alliances and multi-academy trusts requested the Greenwich team to help it build teacher-led systematic research into teachers' everyday practice. This gave rise to the project Teachers as Researchers that formed this study. The project was carried out for 4 years from 2015 to 2019 and involved 150 early years, primary and secondary school teachers from London and Kent. 
The headteachers of the multi-academy trust schools encouraged voluntary participation of their teachers in action research to reflect on and improve their classroom practices.

Teachers were given incentives to take part: fees were paid directly to the University and the course delivered in the school setting and at the end of the school day. Teachers were also invited to register as students at the University, have their final report assessed and be awarded 30 credits from the MA in Education (module: Negotiated Independent Study: Professional Knowledge). Teachers were supported by the university team throughout the whole process of action research and collaboration and offered individual supervision when writing their final reports or disseminating their work through publication and presentations in conferences.

\section{Implementation}

The university team included a professor of Education (with over twenty years' experience working alongside teachers on action research), a research fellow (with expertise in research methodologies and teacher development) and four faculty members who were experts in teacher education, professional development and educational research. The four-year project provided support for teachers and included, during one academic year, at least six ninety-minute afternoon workshops (at intervals of five to seven weeks) to guide the teachers through the steps of action research and collaboration. The study is based on the action-research steps mentioned above: reflect, plan, act, observe and reflect (McNiff and Whitehead, 2005; Kemmis, McTaggart and Nixon, 2014). The articulation between these steps of the action-research cycle and the tasks involved in the facilitation and collaboration (Lofthouse et al., 2016) constituted the main structure of our model (figure 1). A detailed discussion follows below.

In the workshops, participants collaborated intensively with each other and with the University team of facilitators. According to Mitton-Kukner (2016), this type of interaction stimulates reflection about practice and fosters the development of opportunities for professional learning. Further details about the activities in the workshops will be discussed in the section on steps for developing action research.

We facilitated the process of action research by guiding teachers in designing projects, providing support on ethical issues, data collection tools, analysis and research literature to inform action. They identified a specific aspect of their practices that they would like to improve and engage in one cycle of action research. They held discussions with colleagues, observed teaching by other teachers and read related professional and academic articles. All of these informed the action they undertook in class to effect change, as it helped them to identify the types of data to collect and then, with colleagues and the University team, to evaluate their professional actions. Senior leaders, in a supporting role, ensured that teachers did attend the workshops, discussed with them areas for development, provided clarity on aspects of school improvement as a focus for teachers who did not have specific areas of research and offered pedagogical support. Senior leaders additionally created opportunities for teachers to collaborate with colleagues across various departments in their school and other schools of the same trust. They also ensured that outcomes from the action research were disseminated for the professional development of other teachers in the school (presentations in meetings and events and publication on the school website of all the action-research reports). In some cases, senior leaders also supported the participation of teachers in conferences to present their work (e.g., UKLA conference) and contributed to the 
tuition fees for those teachers who wanted to complete the MA (using their thirty credits from our course and, in some cases, the credits gained from their PGCE).

\section{Our model}

The model of conceptualising collaborative action research designed by Lofthouse et al. (2016) defines the nature and implications of the zones of activities between all participants in this study and this has informed our model of collaboration (figure 1). This model includes zones of collaborative, contributory and proximal activities. The zone of proximal activity occurs before collaboration and after collaboration. To facilitate this process, we organised workshops for teachers to discuss their classroom experience of teaching and their knowledge of research and to explore areas of professional development. This enabled us to identify the level of research experience of the participants, by which means we established that the participants would need support in carrying out action research. The zone of contributory activity helped us to identify key roles that the participants have in their schools and the focus of their research. We achieved this by placing them in groups of six, to encourage discussion, reflections and peer review. Each member of the research team was assigned to work with the groups, followed by whole class feedback and questions to refine their areas of research. This activity allowed us to draw on their skills and guide them on the areas of research they would like to explore. The zone of collaborative activity also involved discussion, reflection and peer review. It allowed us to engage the participants in the action research cycle (Kemmis, McTaggart \& Nixon, 2014): reflecting (involved participants in defining the field of action), plan (planning the action), act (implementing the action), observe (evaluation of the action) and reflect (reflection and replanning). These steps will be discussed in detail in the next section. During the contributory and collaborative processes, we supported the teachers by providing them with relevant literature on areas of interest to link theory to practice. We encouraged them to keep a research log and delivered tutorials and lectures on data collection and analysis, ethical guidelines and report writing, all of which were important in promoting research skills. Consequently, we realised that participants became confident about what they want to explore, accessed relevant research materials and supported each other. The proximal activity happening after the collaboration may be expanded and influenced by the outcomes of the collaboration. At this stage, the participants can disseminate their work at conferences or publications with the help of the research team. Throughout these processes, we sought participants' views about engaging in the action research process and samples of their comments are presented in our discussion of the steps of action research. However, a detailed evaluation is planned. 
Figure 1: Model of collaboration/facilitation for the development of teacher action research

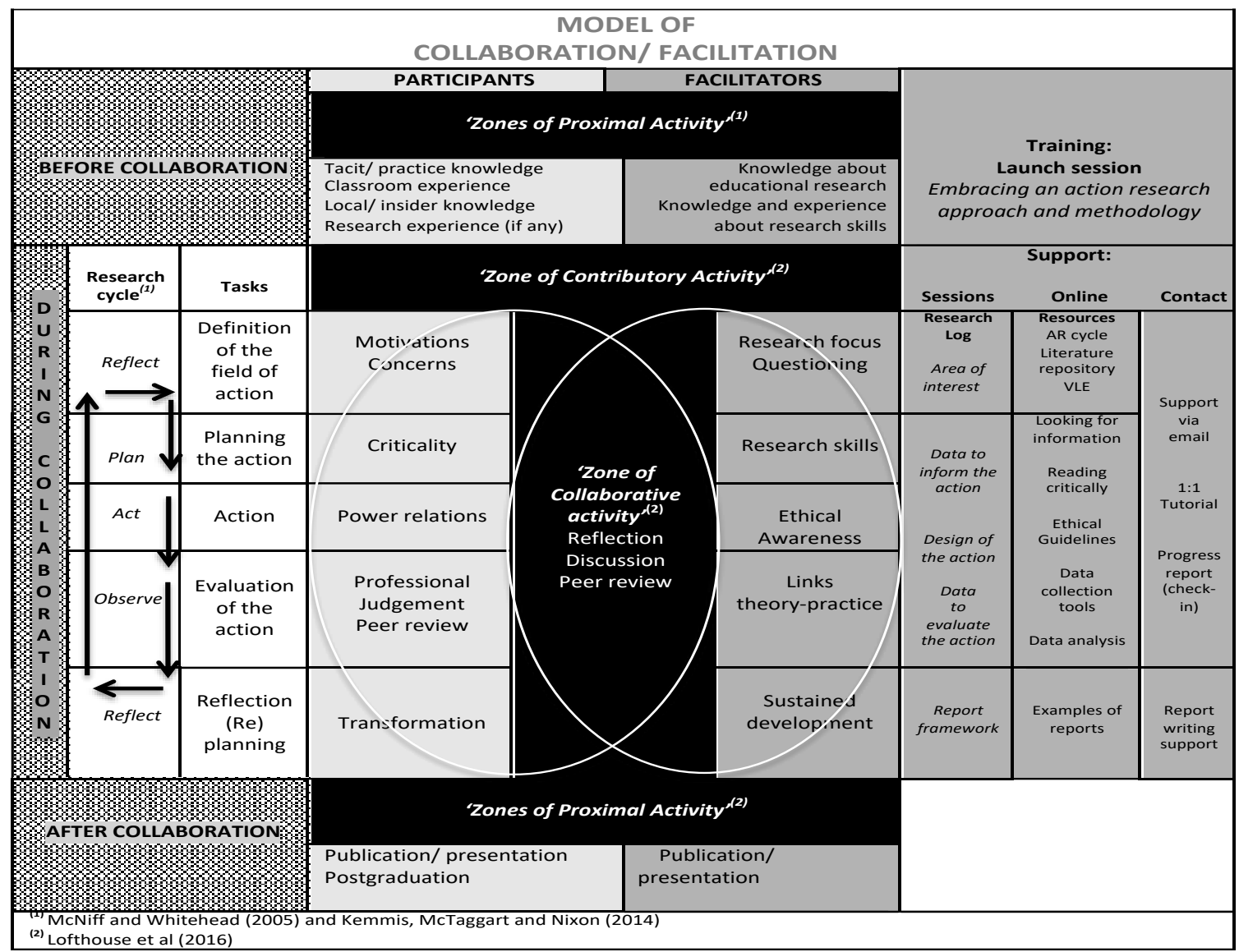

Source: Lambirth et al. (2019)

\section{Steps in developing action research.}

We identified 5 steps in developing teacher-led action research and some challenges in each step as highlighted below.

\section{Defining the field of action}

These involved participants reflecting on their practices and discussing ideas with other teachers and the University team. Doing that encouraged them to use their professional knowledge and classroom practice to identify a specific area of interest they wanted to address. We encouraged them to keep a research log to record, plan, evaluate and reflect and provided them with appropriate support. However, the challenges we encountered included difficulty among participants in addressing motivation and finding a research focus. This may be seen in relation to the notion of teacher agency, with such teacher comments as "teachers should be motivated and willing to do it" and "If it is forced, it will not work." Other unanimous comments from the teachers included "the lack of research knowledge may affect my confidence in this project but willing to work with the team'. We, therefore, argue that schools need to define clear criteria to regulate the recruitment of participants to avoid co-opted participation and "compelled inclusion" (Lambirth \& Cabral, 2017, p. 8). 
Although this may not be the norm, however, we know that, in certain situations, teachers may be persuaded in participating in research.

\section{Planning the action}

Participants were encouraged to read selected literature in their field, challenge each other's ideas and work as peers. The University team played a key role in developing criticality by promoting moments of reporting and discussing the design of the studies, reflection and ethics; the team encouraged cooperative and collaborative working environments using peer assessments and such elements of the pedagogy of facilitation of teacher inquiry (Poekert, 2011) as introducing, wondering, experimenting, evaluating, learning and sharing. Participants commented that this enabled them to "realise the need to incorporate regular research into teaching practice". One said, "the project exceeded my expectations" and others conveyed similar enthusiasm. However, challenges encountered ranged from time allocation, lack of research skills of participants and criticality. To develop this step of the action research cycle, participants received dedicated support at the level of research skills (Ross and Bruce, 2012). Through collaboration, teachers can critically engage with research evidence, reflect on their meanings, gain new perspectives, and change their practice (Procter, 2015).

\section{Action}

We created an opportunity for the participants to reflect and develop their context-awareness with help of teachers from their school, other schools and the University team. This included providing prompts for discussion about ethics and power relations based on ethical guidelines (research log) (BERA 2018). Teachers collected and analysed data about the action (research log: data to evaluate the action). They implemented the action and received specific support via email and individual tutorials based on the use of progress reports (individual check-ins). Teachers found this useful in their professional development, as comments like these confirm: "the project has helped me to think about my practice differently and more critically" and "it helped me to take onboard children's views to make what they are doing interesting and support learning". The challenges encountered included power relations and ethical awareness. However, both the teachers and senior leaders have a shared responsibility for ensuring that the action research process is aimed at improving teachers' professional development. Teachers decided areas of focus for their research and, where applicable, senior leaders provided direction, as mentioned. In this regard, Mockler (2014) recommends that we discuss with teachers the issues of informed consent, voice and ownership, transparency, negotiation and deliberative action in the context of both practitioner inquiry and classroom practice.

\section{Evaluation of the action}

Participants were invited to discuss their experiences and issues associated with the implementation of the action by evaluating their practice (Poekert 2011) and analysing the data collected. The University team promoted moments of questioning and facilitated discussions about the differences between practice and theory. Comments from the teachers showed how this had a positive effect on their development; for example: "it made me look more closely at how I can change my practice and be a better teacher"; "the journey has been a transformative one for me and my pupils" and "it made me think about my 
practice in a more critical way". Some teachers considered the need to promote autonomous learning as an important aspect of engaging in this research: "students need to be challenged and discover things by themselves", while others asserted that "lessons were livelier, children appeared more enthusiastic about their learning and took more control over it”. Despite the support, the challenges identified included participants' lack of confidence in making a professional judgment, conducting peer review and linking theory to practice. The achievement of an agency should emanate from the "complex interplay of individual capacity and collective cultures and structures" (Biesta et al., 2017, p.52). We may argue that engaging in this process has resulted in some level of improvement among the participants, though the issues encountered will further guide us on how best to support their professional development.

\section{Reflection and (re)planning}

Participants and facilitators were involved in group reflections and discussions based on a set of transformation stimuli. These included: the confirmation or change of perspectives; innovation; learning opportunities; sustained development. These group reflections and discussions about the results of the action were the starting point for the development of the topics to be included in the final report (research log: report framework). To support this step, participants received the reporting framework and guiding questions for each section and were given access to examples of reports. The consensus was that it encouraged transformative professional learning: "the journey has been a transformative one, both within me and pupils" and "it was helpful to use my findings to reflect on my practice and how to develop that of others and school provision". This process promoted confidence about engaging in action research, but we also faced challenges - such as the weak ability of participants to share good practices and collaborate with others as co-researchers. However, we created an opportunity for them to review their learning through various activities to support knowledge-sharing and collaboration. This enabled them to disseminate outcomes by moving from a transmission model to a transformative model of professional learning (Kennedy, 2007) - vital in helping them accomplish the process of action research (figure 1).

\section{Conclusions and limitations}

This project shows that facilitated action research can be used as a tool for promoting professional learning and fostering change. It allows teachers to learn from their interactions with each other and support from the University team. In our case, this was achieved by following the steps of the action-research process and model of collaboration as this study confirms. However, each step has its challenges, and the university team should help teachers or students overcome these challenges by creating opportunities for them to review their learning through well-structured learning activities to promote collaboration, research knowledge and skills. The model we created (figure 1) helped us to theorise practice and construct knowledge based on our experience, driven by the interpretation of the contexts we worked in. This model is therefore contextualised by nature. The model is currently used by colleagues and schools engaged in action research to improve teachers' practices and it contributes to the existing body of knowledge.

Carrying out such a project with multi-academy trusts for four years has influenced the creation of an action-research model of collaboration and facilitation. However, this should 
not be taken at face value, as efforts should be made to consider all facets of successful action research through collaboration and facilitation. This may involve considering the various approaches to action research and deciding which approach suits the participants, as our model may be tailored to specific research needs. We shall review the effectiveness of the model by carrying out interviews with colleagues and schools currently using this model to promote action research.

\section{Reference List}

Biesta, G., Priestley, M. and Robinson, S. (2017) 'Talking about education: exploring the significance of teachers' talk for teacher agency.' Journal of curriculum studies, 49(1), 38-54. Available at: https://doi.org/10.1080/00220272.2016.1205143 (Accessed: 20 March 2018).

British Educational Research Association (BERA) (2014) 'Research and the Teaching Profession.' Available at: https://www.bera.ac.uk/project/research-and-teacher-education (Accessed: 15 June 2015).

British Educational Research Association (BERA) (2018) 'Ethical guidelines for educational Research.' $4^{\text {th }}$ edition. Available at: https://www.bera.ac.uk/publication/ethical-guidelines-foreducational-research-2018 (Accessed: 15 October 2020).

Bleicher, R. (2014) 'A collaborative action research approach to professional learning.' Professional development in education, 40(5), 802-821. Available at: https://doi.org/10.1080/19415257.2013.842183 (Accessed: 12 June 2018).

Bryan, H. and Burstow, B. (2016) 'Leaders' views on the values of school-based research: contemporary themes and issues.' Professional development in education, 43(5), 1-17. Available at: https://doi.org/10.1080/19415257.2016.1238835 (Accessed: 14 June 2018).

Cordingley, P. (2013) The contribution of research to teachers' professional learning and development. Research and Teacher Education: the BERA-RSA Inquiry. London: British Educational Research Association. Available at: http://www.curee.co.uk/publication/contribution-research-teachers\%E2\%80\%99professional-learning-and-development (Accessed: 14 June 2018).

Department for Education (DfE) (2014) 'Improving the quality of teaching and leadership.' (Policy issue - updated, 2nd September 2014). Available at: https://www.gov.uk/government/publications/2010-to-2015-government-policy-teaching-and-school-leadership (Accessed: 22 September 2015).

DfE (2016) 'Standard for teachers' professional development.' Available at: https://assets.publishing.service.gov.uk/government/uploads/system/uploads/attachment da ta/file/537030/160712 - PD standard.pdf (Accessed: 15 October 2020).

Kemmis, S. (2010) 'What is to be done? The place of action research.' Educational action research, 18(4), 417-427. Available at: https://doi.org/10.1080/09650792.2010.524745 (Accessed: 22 September 2015). 
Kemmis, S., McTaggart, R. and Nixon, R. (2014) The action research planner: doing critical participatory action research. Singapore: Springer. ISBN: 978-981-10-1350-8

Kennedy, A. (2007) 'Continuing professional development (CPD) policy and the discourse of teacher professionalism in Scotland.' Research papers in Education, 22(1), 95-111.

Available at: https://www.tandfonline.com/doi/abs/10.1080/02671520601152128 (Accessed: 25 February 2018).

Lambirth, A. and Cabral, A. (2017) 'Issues of agency, discipline, and criticality: an interplay of challenges involved in teachers engaging in research in a school's performative context.' Educational action research 25(4), 650-666. Available at: https://doi.org/10.1080/09650792.2016.1218350 (Accessed: 02 February 2018).

Lambirth, A., Cabral, A., McDonald, R., Philpott, C., Brett, C. and Magaji, A. (2019) 'Teacherled professional development through a model of action research, collaboration and facilitation.' Professional Development in Education. Available at:

https://doi.org/10.1080/19415257.2019.1685565 (Accessed: 08 March 2020).

Lofthouse, R., Flanagan, J. and Wigley, B. (2016) 'A new model of collaborative action research; theorising from inter-professional practice development.' Educational action research, 24(4), 519-534. Available at: https://doi.org/10.1080/09650792.2015.1110038 (Accessed: 25 February 2018).

McNiff, J. and Whitehead, J. (2005) Action research for teachers: a practical guide. London: David Fulton Publishers. ISBN: 9781843123217

Mitton-Kükner, J. (2016) 'Time constraints experienced by female teacher researchers in Canada and Turkey: challenges to developing an autonomous professional learning mindset.' Professional development in Education, 42(4), 628-646. Available at: https://doi.org/10.1080/19415257.2015.1073607 (Accessed: 14 June 2018).

Mockler, N. (2014) 'When research ethics become everyday ethics: the intersection of inquiry and practice in practitioner research.' Educational action Research, 22(2), 146-158. Available at: https://doi.org/10.1080/09650792.2013.856771 (Accessed: 14 June 2018).

Mockler, N. and Groundwater-Smith, S. (2015) 'Seeking for the unwelcome truths: beyond celebration in inquiry-based teacher professional learning.' Teachers and teaching, 21(5), 603-614. Available at: https://doi.org/10.1080/13540602.2014.995480 (Accessed: 14 June 2018).

National College for Teaching and Leadership (NCTL) (2015) 'What makes great pedagogy and great professional development: final report.' Available at:

http://dera.ioe.ac.uk/22157/1/What makes great pedagogy and great professional development final report.pdf (Accessed: 10 January 2016).

Poekert, P. (2011) 'The pedagogy of facilitation: teacher inquiry as professional development in a Florida elementary school.' Professional development in Education, 37(1), 19-38.

Available at: https://doi.org/10.1080/19415251003737309 (Accessed: 27 March 2017). 
Procter, R. (2015) 'Teachers and school research practices: the gaps between the values and practices of teachers.' Journal of Education for Teaching: International research and pedagogy, 41(5), 464-477. Available at: https://doi.org/10.1080/02607476.2015.1105535 (Accessed: 12 April 2019).

Ross, J. and Bruce, C. (2012) 'Evaluating the impact of collaborative action research on teachers: a quantitative approach. 'Teacher development, 16(4), 537-561. Available at: https://doi.org/10.1080/13664530.2012.734746 (Accessed: 22 September 2015). 